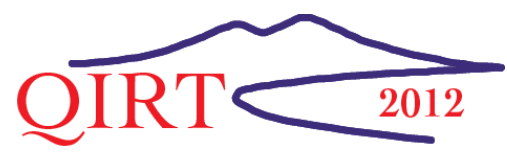

http://dx.doi.org/10.21611/qirt.2012.373

$11^{\text {th }}$ International Conference on Quantitative InfraRed Thermography

\title{
Heat Conductance Determination using Infrared Thermography.
}

\author{
by Jean-Marie Buchlin ${ }^{1}$, Guillaume Diquas ${ }^{1}$, Philippe Planquart ${ }^{1}$ and Michel Renard ${ }^{2}$ \\ ${ }^{1}$ von Karman Institute for Fluid Dynamics- Rhode-Saint-Genèse, Belgium \\ ${ }^{2}$ DREVER Int. SA, Angleur, Belgium
}

\begin{abstract}
The knowledge of heat conductance between two solids is often required when designing thermal systems. A typical example is the continuous annealing of moving strip based on the roll quench process as illustrated in figure 1a. The hot strip is cooled through heat transfer on its contact surface with the roll. The overall heat transfer coefficient depends strongly of the contact resistance strip-roll shell. From literature shows that such parameter depends on the nature of the material, the surface roughness, temperature level and the contact pressure, which is function of the tensile strength.
\end{abstract}

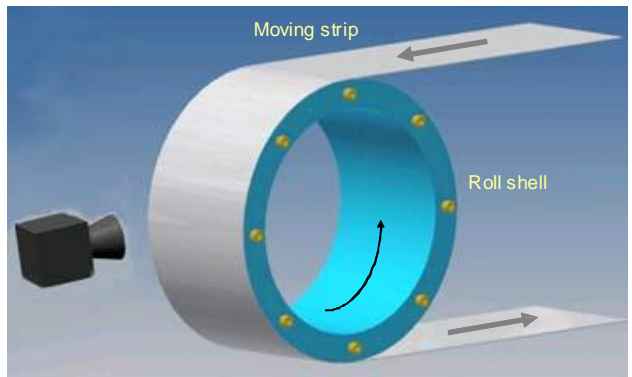

a- Principle

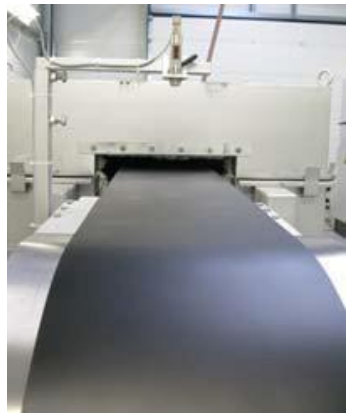

b- Front view

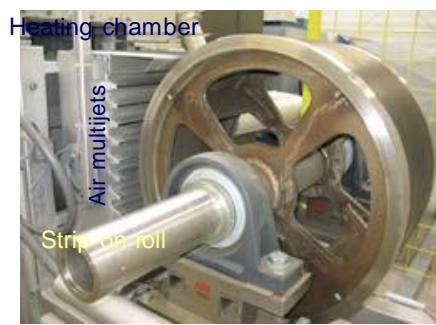

c- side view

Fig.1. Rolled strip quenching system

An experimental investigation has been undertaken at the von Karman Institute to establish correlation of contact thermal conductance in roll quench system. A dedicated facility has been constructed as shown in figure 1-b. It consists of a steel band of $0.3 \mathrm{~m}$ wide and $0.5 \mathrm{~mm}$ thick, entrained by a pair of rolls and passing through a radiant heating unit to get a maximum temperature of $600^{\circ} \mathrm{C}$. Then the strip is put in contact with a cylindrical steel shell of $0.8 \mathrm{~m}$ in diameter and $0.02 \mathrm{~m}$ thick. After what the strip undergoes additional cooling by means of air multi jets. The line allows strip velocity from 0.25 to $0.5 \mathrm{~m} / \mathrm{s}$. The shell is instrumented with comb of thermocouples mounted within the shell thickness. The thermocouples are connected to a telemetry acquisition system. The external face of the strip is black painted and scanned by an IR camera at the roll location as depicted in figure $1 b$.

Figure $2 \mathrm{a}$ shows a typical thermogram of the strip on the roll in the case of periodic state reached after a certain number of rounds when cooling the roll shell by means of an air multijet unit as depicted in Figure 1c. The thermogram indicates that the temperature field of the strip is not uniform. In particular a clear increase of temperature is observed close to the edge revealing that the roll cooling is not efficient in this area; The temperature profile along the line $A B$ of the thermogram plotted in Figure 2-b quantifies this defect. It shows that the cooling on the edge is very poor because the initial strip temperature of $310^{\circ} \mathrm{C}$ is almost retrieved. Such a defect is explained by a loose of contact between the strip and the roll is this region. However, the comparison of the IR and thermocouple measurements in the central part of the thermogram, where the striproll junction is very good, points out that the strip temperature $\left(265^{\circ} \mathrm{C}\right)$ is very close to the roll surface temperature. Such finding is the sign of a large contact heat conductance.

The paper will describe the facility and the involved measurement techniques. The thermal cooling model and the associated thermal conductance definitions will be presented and typical illustrative results will be discussed. 
A

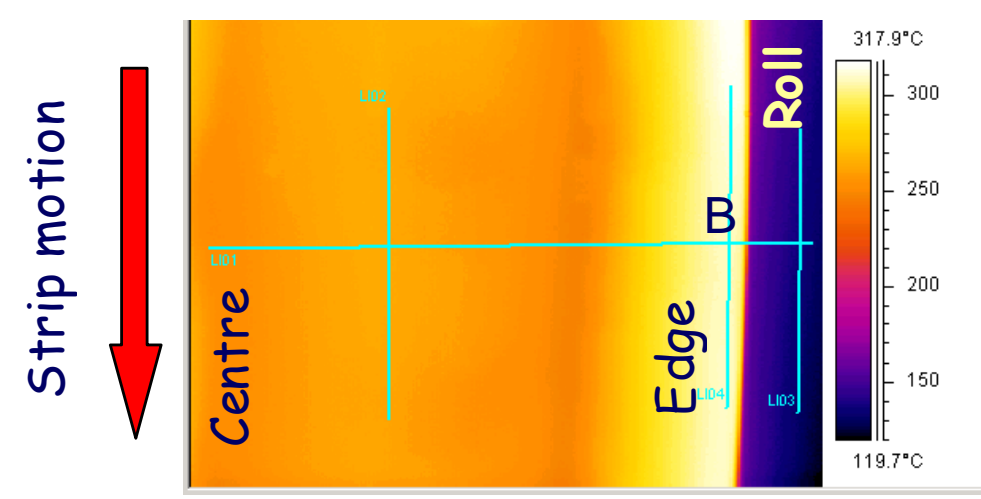

a- Thermogram

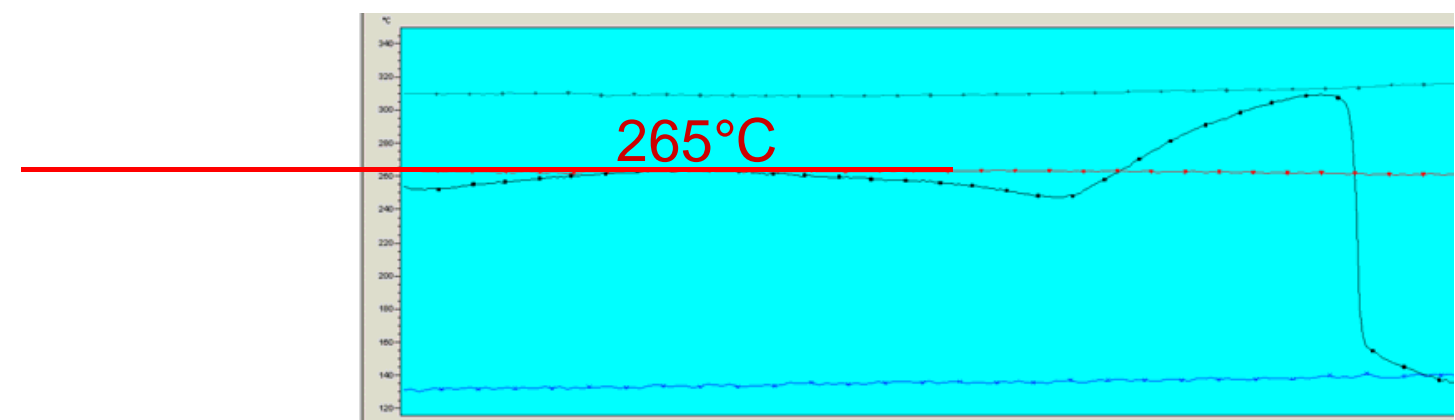

b- Horizontal temperature profile of the strip

Fig.2. Infrared Thermography Data. 